\title{
EFEITOS DA LEI DE TERRAS NAS RELAÇÕES SOCIOESPACIAIS NA AMAZÔNIA
}

\section{EFFECTS OF LAND LAW IN SOCIOSPATIAL RELATIONS IN AMAZON}

\author{
Natalia Altieri Santos de Oliveira ${ }^{1}$ \\ Luly Rodrigues da Cunha Fischer ${ }^{2}$
}

\section{RESUMO}

Analisa a implementação da Lei de Terras de 1850 na Amazônia e seus reflexos socioespaciais. Utiliza o método interpretativo histórico, e as técnicas de pesquisa bibliográfica. Justifica a pesquisa pela importância do entendimento da origem da estrutura agrária para a solução de problemas contemporâneos. Apresenta o processo de colonização da Amazônia, o contexto fundiário e político em que a Lei de Terras foi editada e seus reflexos nesta região. Analisa as disposições da referida Lei e de sua regulamentação. Discute os efeitos das disposições legais na Amazônia. Conclui que a Lei de Terras consolidou o latifúndio e provocou exclusões sociais.

Palavras-chave: Fundiário; Lei de Terras de 1850; Amazônia; História do Direito; Propriedade.

\begin{abstract}
Analyzes the implementation of the 1850 Land Law in the Amazon and their socio-spatial consequences. Use historical interpretive method, and techniques of literature. Justifies the search for the importance of understanding the origin of the agrarian structure to solve contemporary problems. Presents the process of colonization of the Amazon, the land and political context in which the Land Law was enacted and its effects in this region. Analyzes the provisions of the Act and its regulations. Discusses the effects of the legal provisions in the Amazon. It concludes that the Land Law consolidated the latifundium and provoked social exclusion.
\end{abstract}

Keywords: Land; Land Law of 1850; Amazon; History of Law. Property.

\footnotetext{
${ }^{1}$ Bolsista CAPES. Mestranda em Direitos Humanos e Meio Ambiente - Programa de Pós Graduação em Direito da Universidade Federal do Pará (Brasil). Email: nataliaaaltieri@ gmail.com

${ }^{2}$ Doutora em Direito da UFPA/Université Paris XIII. Pará (Brasil). Email: lulyfischer@ yahoo.com
} 


\section{INTRODUÇÃO}

A promulgação da Lei de Terras de 1850 é considerada por diversos autores como um dos marcos fundiários legais mais importantes do país, pois introduziu a noção de propriedade privada no território nacional, na medida em que foi a primeira lei que previu a possibilidade de transferência da propriedade (e não apenas da posse), sendo apontando ainda alguns autores que esse momento histórico contribuiu para a consolidação dos latifúndios em vez de democratizar o acesso à terra, impactando também nas relações sociais (TRECCANI, 2011; BENATTI, 2003).

Nesse sentido, a análise dos efeitos socioespaciais da implementação da lei de terras e do Decreto nº 1.318 de 1850 na Amazônia à época ${ }^{3}$, se faz importante por ser uma parte da federação brasileira com mais problemas fundiários, sendo necessário o entendimento dos efeitos que esta norma produziu na região, não apenas na configuração espacial, mas também nas relações sociais.

O objetivo deste artigo é analisar os efeitos da Lei $n^{\circ} 601$ de 18 de setembro de 1860 na Amazônia com o fim de verificar como as regras de acesso à terra criadas pela lei de terras impactaram nas relações socioespaciais nesta parte do país, por meio de revisão bibliográfica.

A metodologia de análise utilizada na pesquisa foi a interpretativa histórica. A técnica de coleta de dados empregada foi a pesquisa bibliográfica de obras jurídicas e históricas sobre a aplicação da lei de terras no âmbito nacional e os que tratam dos reflexos da norma no Pará.

A exposição dos resultados da pesquisa foi organizada em três partes. Primeiramente, será apresentado uma breve contextualização da Amazônia desde a colonização até o Brasil império, mais especificamente a época de vigência Lei de Terras. Na segunda parte será apresentado brevemente o contexto fundiário e normativo em que foi editada a Lei $\mathrm{n}^{\circ} 601$ de 1850, com a apresentação do sistema sesmarial e o período da posse, além das disposições da lei de terras e o seu decreto regulamentador. Por fim, serão relatados os efeitos socioespaciais da lei de terras na área que correspondia à Amazônia atual, como o contexto do extrativismo da borracha.

\footnotetext{
${ }^{3}$ Se faz importante destacar que o que se conhece atualmente como Amazônia teve um processo de colonização que culminou no desenvolvimento da monocultura e do extrativismo de cunho familiar (FISCHER, 2014).
} 


\section{BREVE CONTEXTUALIZAÇÃO DE AMAZÔNIA DESDE A COLONIZAÇÃO ATÉ O BRASIL IMPÉRIO}

Para se entender a realidade da Amazônia, se faz necessário compreender também os acontecimentos históricos formadores desse espaço (NUNES, 2012), já que esta é conhecida como um campo de conflitos entre os impérios europeus, em especial Portugal e Espanha, na medida em que o atual território que compreende a Amazônia brasileira estava em grande parte sob domínio territorial o império espanhol (REIS, 2001).

O estado do Maranhão e Grão Pará, criado na época de 1621, por meio da Carta Régia de 13 de julho de 1621, corresponde em boa parte aos contornos do que atualmente é conhecido como Amazônia brasileira (CHAMBOULEYRON, 2010). Inicialmente esta área não despertou interesse do governo português, fazendo com que sua colonização fosse considerada como tardia em comparação com a que ocorrera no litoral e no sudeste do Brasil (MEIRA FILHO, 1976), com a característica de ser uma unidade autônoma diretamente subordinada à Portugal (SANTOS, 2008).

O povoamento desta região iniciou-se com a finalidade de se expulsar os holandeses, ingleses e franceses que estavam explorando as chamadas "drogas do sertão". Desse processo de expansão, nasceram núcleos fortificados que mais tarde seriam as cidades de São Luís, Belém, Macapá e Manaus (CARDOSO; MÜLLER, 2008).

O processo de colonização amazônico (Maranhão e Pará), desde o século XVII, é resultado de inúmeras tentativas de impulso populacional, na medida em que a Amazônia era vista como uma área ainda não povoada e que o domínio do território somente se daria mediante a fixação dessas pessoas, principalmente por meio da agricultura. Esse processo de migração, ainda nos séculos XVI e XVII, se deu não apenas com o deslocamento de pessoas de Portugal ou de outras áreas europeias para o Maranhão e Pará, mas também da própria movimentação (forçada) de indígenas, que, quando livres, formavam nas proximidades das comunidades portuguesas aldeias decorrentes do processo de descimiento (CHAMBOULEYRON, 2010).

No que tange ao aspecto espacial, a Amazônia, durante a época da colonização, se mostrava como sendo um espaço de guerra, com a existência de 40 fortificações espalhadas, tudo com a finalidade de consolidar a soberania portuguesa em detrimento às dos invasores, Além disso, os próprios núcleos que posteriormente dariam base para o crescimento das 
cidades, possuíam construções tipicamente portuguesas, com casas de arquitetura de casa grande, ruas estreitas e calçadas de paralelepípedo, por exemplo (BENCHIMOL, 2009).

Anos após, durante as décadas de 1830 e 1860 - mesmo período de aplicação da Lei de terras, como será explanado posteriormente -, diante de um contexto de formação do Estado imperial, os elementos constituintes do espaço amazônico são consolidados, podendose afirmar que esta é a origem do que se entende como atualmente como Amazônia brasileira. Este fato se dá em razão de ter sido nesta época em que o imperialismo se espalhava pelo mundo, que a necessidade de se delimitar as fronteiras do norte do Brasil para manter a unidade territorial, tendo sido realizado a assinatura de diversos tratados internacionais. Até então, a Amazônia era uma região pouco conhecida tanto na Europa quanto no próprio Brasil, e sua produção era criticada pelos europeus em razão do uso de técnicas primitivas, ainda que tivesse mercado certo e seguro no próprio continente europeu e nos Estados Unidos (NUNES, 2012).

Nesta época a economia na Amazônia inseria-se no mercado internacional com a indústria da borracha, em razão da demanda da fabricação de produtos faziam uso dessa matéria prima, como bicicletas e automotores. A economia na Amazônia, durante o período de 1850 a 1910 (período conhecido como o primeiro grande ciclo da borracha) cresceu cada vez mais em razão das demandas internacionais (VIRGOLINO, 2015).

Nessa perspectiva, pode-se afirmar que o que atualmente conhecemos como Amazônia se firmou durante a época do Brasil império, mesmo lapso temporal em que houve e edição da lei de terras. Assim sendo, esta área, que se encontrava em evidência enquanto mecanismo de afirmação do Estado Império brasileiro, passou a ser considerada, pela primeira vez até então, como sendo uma área considerada estratégica (NUNES, 2012).

$\mathrm{Na}$ Amazônia, as relações sociais estão pautadas em sua grande maioria a partir de sua ligação com a terra, sendo fundamental para estas relações a segurança jurídica, na medida em que esta é uma região historicamente de conflitos e interesses diversos dos mais variados grupos sociais para o acesso à terra e a manutenção deste direito (ROCHA, 2014).

Durante o século XVIII, é notável a existência de dois tipos de relações e de uso da terra: de um lado, havia a produção de bens de exportação, como o café, cacau e borracha, que faziam uso de mão de obra escrava; de outro lado, havia as pequenas posses familiares, que apesar de não estarem previstas legalmente (já que as sesmarias tinham um fim diverso e não abrangiam essas pequenas posses), eram as responsáveis pelo abastecimento dos centros urbanos. Cumpre destacar que neste período a terra em si não tinha valor, não era considerada 
uma mercadoria, mas sim tudo aquilo que se poderia extrair da floresta era que era comerciável (TRECANNI, 2009).

\section{LEI DE TERRAS}

O acesso à terra (urbana ou rural) historicamente não ocorre de maneira igual, na medida em que a estrutura fundiária, desde a sua origem, com a implementação do sistema sesmarial, se mostrou como sendo excludente para uma parcela da sociedade (TRECCANI, 2011).

A origem da estrutura agrária nacional encontra-se no Direito Português, haja vista que não houve a criação inicial de uma legislação própria para a colônia (BENATTI, 2003). Com a ocupação portuguesa em 1500, todas as terras brasileiras passaram a pertencer a Portugal, cabendo ao Rei a permissão ou não do acesso a estas (TRECCANI, 2009).

O histórico dos instrumentos legais de organização das terras inicia-se com as Ordenações Portuguesas (COSTA; CRUBELATI; LEMES; MONTAGNOLI, 2011), mas foram as Ordenações Filipinas de 1603 (ALMEIDA, 1870) as normas que de fato disciplinaram a primeira forma de distribuição de terras em nosso ordenamento nacional, gerando problemas fundiários que repercutem na contemporaneidade, decorrentes da imprecisão de suas delimitações (BENATTI, 2003).

Inicialmente, com a colonização portuguesa, o acesso à terra deu-se por meio do sistema sesmarial, aplicado no Brasil por meio das Ordenações Portuguesas no Brasil. Nesse sentido, cumpre destacar ainda que não foi levado em consideração que o sistema sesmarial era oriundo de uma realidade fundiária completamente diversa à existente no Brasil à época. A exclusão social provocada por esse regime se deu em virtude do sistema sesmarial privar toda e qualquer pessoa que não tivesse posses suficientes para receber a concessão de terra, podendo este fato ser considerado um dos primeiros marcos temporais no que tange à exclusão social do acesso à terra (BENATTI, 2003).

Durante o período em que o sistema sesmarial esteve em vigor no Brasil, diversas leis, decretos, cartas régias, alvarás, provisões, resoluções e avisos foram editados, o que culminou em uma confusão legislativa e descontinuada (NOZOE, 2006). Entretanto, é possível apontar a existência de algumas cláusulas essenciais para que uma carta de sesmaria fosse considerada válida, como a questão do aproveitamento, que consistia na exigência de "lavrar" a terra, sendo esta uma exigência que justificava a concessão das cartas; a medição e 
demarcação, que era considerada como sendo uma obrigação que era dificultada pela escassez de técnicos capacitados bem como em razão da imensidão do território brasileiro; o registro da carta em livro próprio; o pagamento de foro, que variava em razão do tamanho da terra e a sua distancia das cidades; e por fim, a confirmação da carta pelo Rei português (ROCHA et al, 2010).

Ante a ausência de um regime único, bem como os abusos que este fato deu margem, foi editada a Resolução ${ }^{\circ}$ 76, de 17 de julho de 1822, que suspendeu a concessão de novas sesmarias até que fosse convocada Assembleia Geral Constituinte, determinando ainda que aqueles que estivessem na posse deveriam permanecer na terra (NOZOE, 2006).

Após a suspensão do regime sesmarial, as propriedades no Brasil passaram a dividirse entre as que eram oriundas das sesmarias confirmadas; as posses ilegítimas que se eram as sesmarias caídas em comisso em razão do descumprimento de alguma cláusula; e posses estabelecidas em terras públicas sem qualquer alvará do poder público (ROCHA et al, 2010). Cumpre destacar, nesse sentido, que as posses ilegítimas se expandiram em demasia, motivo pelo qual tal período passou a ser conhecido como período áureo da posse (MATTOS NETO, 2006).

Portanto, durante 28 anos o Brasil ficou sem uma regulamentação de acesso à terra, facilitando a dissipação da posse sem autorização ou fiscalização oficial do governo (BENATTI, 2003). Neste período, o posseiro ocupou não apenas as sesmarias abandonadas ou não cultivadas, mas também alguns latifúndios pouco explorados (ARAÚJO, 2010).

Assim, esse período impulsionou e consolidou de vez, os grandes latifúndios, justamente em razão da ausência de norma legal que regulasse o acesso à terra, bem como a abstenção por parte do governo português no tocante às fiscalizações das próprias cartas concedidas anteriores à suspensão do regime sesmarial, na medida em que muitos foram os casos em que houveram a expansão da terra (ROCHA et al, 2010).

Apesar de toda a discussão ensejando a criação de uma lei que finalmente regulasse o acesso à terra, nada foi feito de concreto na Constituinte de 1824, pois, ainda que houvesse um projeto relativo ao tema, foi aprovado apenas no artigo 179 que previa o pleno direito de propriedade, e nos casos que o poder público exigisse o uso da propriedade (única exceção prevista na lei), o proprietário seria previamente indenizado. Contudo, o fato de ter garantido o pleno direito de propriedade em nada alterou a situação em que encontrava o Brasil, na medida em que garantir tal direito pleno não era o mesmo criar mecanismos que 
possibilitassem o exercício deste direito constitucional; ou seja, permanecia um direito com pouca exigência e aplicabilidade de fato (ROCHA et al, 2010).

A discussão na Constituinte pairava em como promover a colonização efetiva das terras, sem que houvesse a doação ou ocupação desordenada das mesmas. A ideia central era povoar o Brasil, mas sem que para isso houvesse a perda de mão de obra, ao passo em que o tráfico de escravos estava próximo do fim (CARVALHO, 1981). Nesse sentido, é notável que se buscava muito mais a normatização da colonização efetiva do que de fato criar mecanismos de acesso à terra, ou até mesmo criar meio de regularizar a situação pendente no que tangia às sesmarias caídas em comisso (e portanto, não eram consideradas propriedade) e as posses irregulares (fossem em área privada ou pública).

A ideia era criar um mecanismo que ao mesmo tempo em que proporcionasse a criação de um mercado formal de terras e fomentasse a colonização europeia, não fosse criado possibilidades reais de acesso à terra nem houvesse um mercado de trabalho livre, fazendo com que os novos trabalhadores imigrantes ficassem sem escolhas a não ser trabalhar nas fazendas, por meio da servidão, principalmente quando se levasse em conta os casos em que as passagens dos imigrantes eram subsidiadas pelos fazendeiros. A finalidade principal era criar formas de ter uma economia agroexportadora que pudesse competir com os Estados Unidos, mantendo, assim, a sua sociedade agrária (HOLSTON, 2013).

A lei $\mathrm{n}^{\circ} 601$ de 18 de setembro de 1850 foi promulgada com o objetivo de regular as terras devolutas do Império, bem como as terras que eram possuídas por meio de título de sesmaria que não haviam preenchido todos os requisitos $\left(\operatorname{art.} 1^{\circ}\right)$. A finalidade principal da lei era por fim ao caos que imperava até então em razão da ausência de normais que regulassem o acesso à terra, passando a distinguir o que era de propriedade privada e o que era de propriedade pública (BENATTI, 2003). Foram criadas quatro soluções para que houvesse o reconhecimento da propriedade que até então se encontrava irregular: a carta de sesmaria poderia ser revalidada (ainda que não tivesse preenchido as demais exigências legais anteriores para a comprovação do cultivo da terra); a legitimação das posses; as compras das terras devolutas; e por meio de doação (sendo este último aplicável apenas nas faixas de fronteira) (TRECCANI, 2009).

No que diz respeito às sesmarias confirmadas, a Lei de terras tinha como objetivo criar um mecanismo que consolidasse de vez a propriedade que era oriunda destas, afastando de vez a possibilidade das mesmas perderem o caráter de propriedade em razão de revogação vinda por Parte do reino de Portugal. A solução encontrada foi a garantia do domínio das 
mesmas sem que para isso precisasse ocorrer a revalidação das mesmas, conforme se extrai dos artigos 21 e 22 do Decreto 1.318 de 1854.

O problema das sesmarias concedidas, por sua vez, era a sua revalidação e legitimação das posses. Faz-se mister salientar que "muitas sesmarias concedidas antes de 1822 haviam caído em comisso e que todas as propriedades ocupadas após aquela data eram posses não legitimadas" (CARVALHO, 1981, p. 42). Sendo assim, fazia-se imprescindível que as terras (propriedades ou meras posses) fossem medidas e devidamente tituladas, sob pena de serem consideradas como terras devolutas.

Aqueles que, a partir da promulgação de tal lei se apossassem das terras públicas ou alheias seriam despejados das mesmas e não teriam direito a qualquer indenização oriunda das benfeitorias que porventura tivessem feito. Tal situação assim se explicava em virtude de tal ocupação irregular passar a ser considerada como um crime, limitando, assim, o acesso à terra à quem apenas dispusesse de capital suficiente para comprá-las, excluindo aquele que apenas detivesse de sua força laboral.

Mas estas não eram as únicas características da lei de terras. Além da proibição do acesso à terra por modo diverso da compra (artigo $1^{\circ}$ ), a lei revalidava as sesmarias e outros tipos de concessões que foram expedidas pelo governo (fosse ele português, no caso das cartas de sesmarias, fosse o próprio governo imperial brasileiro, no caso de outros tipos de concessões), conforme destacava o artigo $4^{\mathrm{o}}$; assegurava e legitimava as posses que foram adquiridas por meio de ocupação primária ou pela compra além de se acharem cultivadas ou com o princípio de cultura e moradia habitual (artigo $5^{\circ}$ ), tudo antes da vigência da lei.

É possível notar, então, que as características da lei de terras estão circunscritas com o modo de acesso à terra, e por consequência, a propriedade privada, bem como os meios que poderia haver a regularização da posse e das sesmarias caídas em comisso até então. Ademais, uma vez conceituando o que é terra devoluta, e usando uma definição por exclusão, passa-se a criar a possibilidade de se ter um número maior de terras devolutas que propriedade privada de fato.

Além disso, a lei de terras previa a hipótese das terras serem adquiridas por estrangeiros, não criando restrições em aquisições por parte destes, e determinava ainda que os estrangeiros que fossem subsidiados pelo governo teriam que trabalhar em empregos pré estabelecidos pelo Estado, tanto na agricultura quanto em trabalhos públicos ou privados geridos pelo poder público (HOLSTON, 2013). 
Esta determinação estava em consonância com a ideia de usar a mão de obra estrangeira como substituição da mão de obra escrava que estava continuamente sendo alvo de pressões externas, especialmente da Inglaterra. A ideia era subsidiar a imigração europeia e restringir o acesso à terra ao ponto de que os recém chegados não tivessem nenhuma outra opção que não trabalhar para os fazendeiros.

Entretanto, foi apenas em 1854 que a Lei de Terras foi devidamente regulamentada, por meio do decreto $\mathrm{n}^{\circ} 1.318$, que tinha como objetivo executar de fato a de Lei $\mathrm{n}^{\circ} 601 / 1850$, em razão das mais diversas autorizações que foram concedidas com fundamento na lei de terras (FREITAS, 1882). Foi por meio deste decreto que houve a regulamentação da Repartição Geral de Terras Públicas (artigo $1^{\circ}$ do Decreto), além de ter normatizado a medição das terras públicas, a legitimação das terras particulares (fosse por meio das sesmarias não confirmadas, fosse pelas posses mansas e pacíficas), bem como a venda das terras públicas (único mecanismo de aquisição das aludidas terras, com as exceções dos casos em que poderia haver doações).

O registro Paroquial estava previsto no artigo 13 da Lei de Terras e no artigo 93 do decreto 1.318 , tendo sido instituído com o objetivo de se conhecer quantas terras já haviam sido ocupadas, tendo como base as declarações daqueles que se diziam ser seus possuidores. Foi a primeira tentativa de se criar um cadastro de terras por meio do seu recenseamento, na medida em que todos eram obrigados a registrar o que possuíam, ainda que fossem meros posseiros (artigo 91 do Decreto $\mathrm{n}^{\circ} 1.318$ de 1854) ou até mesmo foreiros (ROCHA et al, 2010).

Era um instrumento de decisão acerca do domínio sobre as terras em cada localidade, o que gerou diversas tensões (FERREIRA, 2012). A organização dar-se-ia por meio de freguesias e as declarações seriam registradas pelos párocos responsáveis nos exatos termos ditos pelas pessoas, sem que para tanto necessitasse de documentos para comprovar as alegações que eram feitas, tornando, assim, com que o Registro Paroquial fosse alvo fácil de diversas críticas quanto à sua confiabilidade. Uma das críticas enfrentas pelo instituto foi a de que este não seria suficiente para que o Governo conseguisse discriminar as terras públicas e privadas ou de até mesmo conseguir impor que houvesse o registro das terras (MOTTA, 2005).

O efeitos práticos da lei de terras e do Decreto $\mathrm{n}^{\circ} 1.318$ foram diversos, sendo importante salientar que a lei de terras fez efetivamente foi limitar (ou quase impedir) o acesso à terra dos ex-escravos e dos imigrantes recém-chegados, a partir de então, (ARAÚJO, 
TÁRREGA, 2011) não tendo cumprido a finalidade inicial que em tese era a de diminuir as grandes propriedades, ao passo que apenas aqueles que detinham dinheiro eram quem de fato compravam as terras, além de sempre alegarem que estavam ocupando a terra tempo suficiente para demandar a aplicação do instituto do usucapião (BENATTI, 2003).

Nessa perspectiva, a lei de terras, ao determinar que o acesso a terra dar-se-ia apenas mediante compra e venda, e, portanto, mercantilizar a terra, excluiu grande parcela da população brasileira, em especial os negros, que estavam sendo progressivamente libertos, e os imigrantes que eram recém chegados ao Brasil, na medida muitos não puderam ter acesso à esse direito, pois não possuíam meios financeiros para tanto (TRECCANI, 2011).

Como destaca Trecanni (2009), esta foi uma opção feita pelo legislador brasileiro que optou pela manutenção do latifúndio para que os senhores de terras não ficassem sem mão de obra para suficiente. Ou seja, o camponês, que antes havia sido excluído do acesso à terra por meio da não concessão de sesmarias, com a lei de terras ficou a margem por não possuir dinheiro suficiente, sendo obrigados a se empregarem no latifúndio, assim como os imigrantes, tornando-se mão de obra substituta da escrava.

Ademais, a lei de terras previa a revalidação das sesmarias e das demais concessões que foram efetuadas pelo governo antes de 1850, desde que devidamente preenchidos os requisitos legais impostos, ainda que os anteriores não tenham sido respeitados, pois o que se levava em consideração era principalmente o cultivo e a morada habitual. Isso se dava principalmente em virtude do fato de que as cartas de sesmarias, uma vez não legitimadas, não geravam mais direito à propriedade de quem ocupava as terras.

Podemos assim afirmar que o principal efeito prático encontrado com o advento da lei de terras e seu decreto regulamentador foi a impossibilidade dos pobres terem acesso à terra, excluindo cada vez mais estes de terem o pleno acesso à cidadania, sendo forçados a migrarem do campo para a cidade em busca da afirmação desse acesso ao direito de propriedade (HOLSTON, 2013).

Nessa perspectiva, a lei de terras, ao determinar que o acesso à terra dar-se-ia apenas mediante compra e venda, e, portanto, mercantilizando a terra, excluiu grande parcela da população brasileira, em especial os negros, que estavam sendo progressivamente libertos, e os imigrantes que eram recém chegados ao Brasil, na medida que muitos não puderam ter acesso à esse direito, pois não possuíam meios financeiros para tanto (TRECCANI, 2011). 
Esta lei visava sistematizar a dispersa, anárquica e confusa legislação anterior e foi um dos instrumentos utilizados para, de um lado, garantir o acesso à propriedade aos que detinham os capitais necessários à sua compra e, do outro, frear o acesso à terra dos negros que progressivamente estavam sendo libertados. [...] Além dos negros foram penalizados os imigrantes europeus e asiáticos que o governo brasileiro estimulava a vir se radicar no País. (TRECCANI, 2011, p. 72-75).

Dessa maneira, o uso da expressão "mediante compra e venda", em um primeiro momento poderia até remeter a uma suposta democratização do acesso à terra (ARAÚJO, TÁRREGA, 2011), mas no entanto, o que notou foi a criação de um grupo marginalizado de direitos (no caso o direito ao acesso à terra, com a consequente negativa do acesso à moradia e ao trabalho), pois a inclusão destes com a lei foi meramente formal e não real (CARVALHO, 2014), sendo perceptível que o uso do termo, assim como diversos outros utilizados nas mais variadas normas, denota uma falsa inclusão (BELTRÃO, 2014).

A lei de terras, tal como os regramentos anteriores, foi usada pela elite fundiária, formada em grande parte pelos filhos dos latifundiários formados em Direito pela Universidade de Coimbra, como mecanismo legal de concretização dos seus direitos pessoais, mantendo as desigualdades sociais (HOLSTON, 2013).

Esse contexto fez com que as relações sociais pouco se alterassem, pois o que a lei de terras fez foi confirmar o direito dos proprietários e restringir o acesso dos homens livres, já que os pequenos produtores além de não possuírem dinheiro suficiente para adquirir as terras, não possuíam contatos com os governantes que vendiam as terras (ALMEIDA; BUAINAIN, 2013).

Na Amazônia, a existência de escravos era considerado quase que uma raridade, ante a baixa proporção de escravos para homens livres que existiam (TRECANNI, 2009), era apenas um dos fatores que fizeram com que a crise econômica se acentuasse cada vez mais pois a carência de mão de obra era crescente, já que a região, além de não possuir um clima favorável, não possuía condições financeiras para atrair colonos estrangeiros como o sul e sudeste do Brasil fizeram à época (PRADO JÚNIOR, 1977).

De modo geral, o que se encontrava era existência de direitos de cidadania desiguais durante séculos, e a ocupação ilegal, por meio da posse em geral, é considerada como sendo, ao mesmo tempo, o único meio de acesso à terra para a maioria dos cidadãos, e uma ilegalidade que marca o início do processo de legalização das reivindicações de propriedade (HOLSTON, 2013), contexto este que se insere a promulgação da lei de terras. 


\section{RELFLEXOS SOCIOESPACIAIS DA APLICAÇÃO DA LEI DE TERRAS NA AMAZÔNIA}

Na Amazônia, durante a aplicação da Lei de Terras, há de se destacar que coincidiu parcialmente com o ciclo econômico da borracha, cujo auge foi no final do século XIX, com um crescente processo de migração, em especial de nordestinos (CHAVES, 2011) e de portugueses (BENCHIMOL, 2009).

Cumpre destacar que ainda que a Lei de Terras já estivesse em vigor, a posse da terra no seringal não possuía valor, sendo o seringal implementado como uma empresa desvinculada à terra (MACHADO, 2011). A mão de obra usada nos seringais era a mão de obra livre e branca ${ }^{4}$, inicialmente proveniente da Província do Grão Pará (1850-1890) e depois do nordeste (1890-1910) (VIRGOLINO, 2015).

Nessa perspectiva, ainda que a terra continuasse a não ter valor na economia dos seringais (MACHADO, 2011), era possível notar a ligação intrínseca da estrutura desta economia com a que se fazia presente no restante do país, no que tange ao fato de que, a opção da consolidação do latifúndio através da implementação da lei de Terras, se deu em razão também pela manutenção de oferta de mão de obra para a exportação (TRECCANI, 2011).

Além disso, a consolidação dos latifúndios, que também ocorreu na Amazônia, provocou o aumento dos conflitos sociais na região razão justamente da exclusão social provocada pelos latifúndios que consolidaram em todo o país por meio da lei de terras (DE MESQUITA, 2008), na medida em que a concentração de propriedade é um dos fatores de violência (MARTINS, 1986).

Ademais, foi com a lei de terras que houve a unificação entre o domínio e a posse, fazendo com que o ritmo e modos de ocupação fossem pautados justamente na renda fundiária, criando a possibilidade de expulsar o índio e ali formar uma relação privada com a propriedade (MARTINS, 1998).

Outrossim, há de se destacar ainda a mudança nos deslocamentos ocorridos, na medida em que antes da lei de terras o que se verificava eram deslocamentos de famílias, enquanto que após a edição da Lei no 601 de 1850, o que se passou a notar foi a formação de

\footnotetext{
${ }^{4}$ Os trabalhos dos seringais, ainda que não fizessem uso de mão de obra escrava como as plantações de café, por exemplo, pode ser considerada como um dos antecedentes históricos do uso de mão de obra análoga ao de escravo na Amazônia (CHAVES, 2011).
} 
grupos concorrentes e conflitivos, desenhando um mapa de conflitos pela ocupação da terra e disseminando o que é denominado de "propriedade privada da terra" (MARTINS, 1998).

Esse contexto social é pautado justamente no conflito social entre ricos e pobres, cuja ênfase aumentou ainda mais com a consolidação do latifúndio pela lei de terras. Essa propriedade privada por diversas vezes tem a sua proteção reivindicada por quem violou os direitos de quem trabalhou naquela terra por até mesmo diversas gerações, criando favorecimento de quem possui um documento em detrimento de quem efetivamente ocupou a terra (MARTINS, 1998).

O pobre, não possuidor de documentos que comprovem a sua posse, ainda é quem dá utilidade à terra, e tal como ocorria no sistema sesmarial, o que se verifica é a existência da concepção da terra como bem comum, em especial na Amazônia, existindo casos de confecção de contratos de arrendamento e parceria quando é de interesse do fazendeiro (MARTINS, 1998).

Nesse ponto, é notável a existência do direito proveniente do dinheiro (do posseiro original) e do trabalho (do pobre que lavra a terra), que quase sempre culmina no despejo deste último grupo social, resultado este de grande parte dos litígios envolvendo conflitos agrários. Ademais, na Amazônia ainda é possível evidenciar que um dos traços marcantes desse processo de ocupação territorial é a existência de escravização dos trabalhadores, em especial nas tarefas consideradas como temporárias e transitórias (derrubada da mata e formação das pastagens) (MARTINS, 1998).

Dente os estados que atualmente compõem a Amazônia, é importante destacar a situação da província do Pará (atual estado do Pará), na medida em que esta foi a província com o maior número de registros paroquiais, conforme dados levantados por Muniz (1904), evidenciando a grande adesão da província às exigências da Lei de Terras. De acordo com dados do relatório do Ministério da Agricultura do ano de 1860, com um total de 19.320 registros, subdivididos em 66 freguesias. Quando do final do prazo para registro, o número total de posses cadastradas subiu para 22.611 registros, compreendendo tanto áreas rurais como urbanas.

Analisando os dados compilados pelo mencionado autor, nota-se a existência de municípios (Ourém, Monte Alegre, Ponta de Pedras, Soure, Portel, Quatipuru, Oeiras, Melgaço, Muaná, Itaituba e Cametá) cujos patrimônios das câmaras municipais foram completamente discriminados ainda sob a vigência da lei de terras. Em Itaituba e Cametá, por exemplo, os processos de discriminação encontrados tinham em seu teor o nome de todos 
aqueles que possuíam algum título de posse ou de propriedade, sendo tais informações confirmadas pelo agente técnico à época (MUNIZ, 1904).

Este fato evidencia que nestes municípios a lei de terras funcionou de fato, pois foi possível determinar qual era o patrimônio público desses municípios, ao passo em que nos registros paroquiais encontrados nessas freguesias havia o relato de até mesmo quais eram as medidas das porções de terras que haviam sido doadas e incorporadas ao patrimônio público municipal.

Cumpre destacar ainda que no Pará os efeitos da lei de terras se mantiveram mesmo após a cessação da sua vigência, em 1889, como, por exemplo, o decreto estadual $n^{\circ} 410$ de 1891, que permaneceu em vigor até 1892 (MUNIZ, 1924). Nas considerações iniciais do referido decreto, constava que uma das preocupações do governo paraense era dificultar a constituição de grandes propriedades, e facilitar o estabelecimento de pequenas propriedades, objetivo prático este que também era o da Lei de Terras, além de buscar facilitar a regularização dos posseiros de boa-fé para que pudessem conseguir títulos de propriedade das terras que estavam ocupando, ainda que os mesmos não tivessem preenchidos os requisitos da lei $\mathrm{n}^{\circ} 601$ de 1850.

É possível notar ainda que o Decreto $n^{\circ} 410$, que permaneceu em vigor até 1892 buscava manter a mesma sistemática que a Lei de Terras, na medida em que previa também a possibilidade de revalidação das cartas de sesmarias que haviam caído em comisso e a legitimação das posses (TRECCANI, 2009).

A realidade encontrada foi a de que no referido ano o Governo paraense reconheceu todas as posses e propriedades advindas da legislação do período monárquico, e instituiu o direito de posse para todos aqueles que, na data da Proclamação da República ocupavam terras devolutas, transformando, assim, a posse em propriedade, sem qualquer ônus sob o valor do terreno, sendo obrigado apenas o pagamento do imposto territorial que foi lançado por meio do mesmo decreto (MUNIZ, 1924).

O Decreto estadual $n^{\circ} 410$ de 1891, previa, no seu artigo 16, que os registros das terras possuídas dar-se-iam mediante a declaração dos seus ocupantes ou à vista dos títulos de propriedade respectivos, tudo em conformidade com o regulamento que posteriormente seria promulgado para executar o decreto, semelhante ao Registro Paroquial criado pela lei de terras e regulamentado pelo decreto 1.318/1854, na medida em que se baseavam nas declarações prestadas por aqueles que se diziam ocupar a propriedade, sendo estes de fácil comparação no diz respeito ao seu teor, conforme apresentado por Muniz (1904), sendo 
encontrado por este 156 registros diversos que foram feitos com base da lei $n^{\circ} 410$ de 1891 . O que diferencia é que ao contrário do registro do vigário que tinha a finalidade estatística, o registro estadual tinha como objetivo final a alienação de terras devolutas e/ou a legitimação de posses mansas e pacíficas.

O objetivo do Pará era expandir a sua população, espírito liberal este que foi mantido com a Lei Estadual $n^{\circ} 82$ de 15 de setembro de 1892, já que o Estado fez uso de tal mecanismo com a finalidade principal de promover a efetiva exploração econômica de as terras de seu território sob a garantia da posse e da propriedade.

É perceptível assim, que o Pará adotou uma política contrária a que preceituava a lei de terras, na medida em que a lei de terras permitia o acesso a terra apenas de modo oneroso, como já fora dito, enquanto que o governo paraense estava transformando posse em propriedade por meio diverso, qual seja, não havia a compra efetiva da terra, mas sim a sua mera regularização por meio do pagamento do imposto territorial (MUNIZ, 1924).

É importante destacar por fim, que a existência dessas relações socioespaciais existentes na realidade Amazônica possuem ligação direta com a edição da lei de terras, pois como foi possível evidenciar, as relações socioespaciais de exclusão estão conectadas com o acesso à terra, cujo principal marco normativo de acesso é justamente a lei de terras.

\section{CONCLUSÃO}

O objetivo geral deste artigo era fazer uma análise histórica da legislação fundiária brasileira até a promulgação da Lei de Terras, em 1850, e seu regulamento (Decreto $\mathrm{n}^{\circ} 1.318$, em 1854), além de como todo esse de conjunto de normas foi aplicado na Amazônia e quais as influências socioespaciais criadas.

Primeiramente foi aplicado no Brasil as Ordenações Portuguesas, normas estas que foram criadas em um contexto fundiário completamente diverso ao encontrado no Brasil. Logo após a suspensão do regime sesmarial, instaurou-se no Brasil o período conhecido como "Império da Posse", no qual era predominante o regime de posse, em detrimento da regularização das terras, o que forçava cada vez mais a criação de um ordenamento jurídico próprio que regulasse o acesso à terra.

A Lei de Terras, antes mesmo da sua promulgação já era alvo de diversas críticas, no que tangia a sua aplicabilidade e eficiência, quanto ao fato de ser uma lei que culminaria na 
discriminação das camadas menos favorecidas economicamente, ao passo em que previa que o acesso à terra, a partir da vigência da lei, dar-se-ia exclusivamente pela compra, salvo raras exceções.

Foi possível concluir que a edição de uma lei regulamentadora do acesso à propriedade se fazia necessário até mesmo para o próprio desenvolvimento do Estado, na medida em que foi apenas com o advento da Lei de Terras que foi possível se falar na criação de propriedade privada de fato (antes se tinha propriedade do Estado e semi-estatal).

Neste sentido, foi possível constatar que a lei de terras, enquanto norma que introduziu o conceito moderno de propriedade no ordenamento jurídico brasileiro serviu também como marco legal de exclusão e fomento de conflitos fundiários, alterando as relações sociais e espaciais, especialmente na Amazônia, que sempre foi vista como uma área a ser colonizada como símbolo da soberania portuguesa e brasileira (posteriormente).

No contexto paraense, a conclusão extraída foi a de que a lei de terras, enquanto estava em seu período de vigência, provocou efeitos positivos no estado, sendo possível verificar a existência de municípios (um total de 11, dos 55 existentes à época do fim da vigência da lei de $n^{\circ} 610$ de 1850) como Itaituba e Cametá, com o seu patrimônio municipal completamente e devidamente discriminado. Além disso, no que diz respeito ao decreto estadual n 410 de 1891, foi possível verificar que este muito se assemelhava à extinta lei de terras, e tal como esta, não foi capaz de alterar substancialmente a realidade de acesso a terra, tendo inovado apenas no quesito de acesso gratuito.

Não obstante, ainda se faz necessária a complementação da pesquisa para se verificar se existe ou não mais diplomas legais além daquele que foi estudado no presente trabalho e se estes, de algum modo, foram em face ao que era disposto na lei de terras e houve a criação de um regime de acesso às terras estaduais diverso ao que era previsto na lei nacional.

\section{REFERÊNCIAS BIBLIOGRÁFICAS}

ALMEIDA, Candido Mendes de. Codigo Philippino, ou, Ordenações e leis do Reino de Portugal : recopiladas por mandado d'El-Rey D. Philippe I. Rio de Janeiro : Typ. do Instituto Philomathico, 1870. Disponível em: 〈http://www2.senado.leg.br/bdsf/item/id/242733 > . Acesso em 12 dez 2015.

ALMEIDA, Patrícia José de; BUAINAIN, Antonio Marcio. Os contratos de arrendamento e parceria no Brasil. Rev. Direito GV. vol.9 no.1. São Paulo Jan./June 2013. Disponível em: 
$<$ http://www.scielo.br/scielo.php?script=sci_arttext\&pid=S1808-24322013000100012>. Acesso em: 10 jun 2016.

ARAUJO, Ionnara Vieira de. Regularização fundiária e terras devolutas. Revista da Faculdade de Direito da UFG, [S.1.], v. 33, n. 2, p. 112/127, mai. 2010. ISSN 0101-7187. Disponível em: <http://h200137217135.ufg.br/index.php/revfd/article/view/9861/6737>. Acesso em: 05 de dezembro de 2015.

ARAÚJO, Ionnara Vieira de; TÁRREGA, Maria Cristina Vidotte Blanco. Apropriação de terras no Brasil e o instituto das terras devolutas. Revista da Faculdade de Direito da UERJ, n. 19, 2011. Disponível em: <http://www.epublicacoes.uerj.br/index.php/rfduerj/article/view/1716/1330>. Acesso em 16 jan 2016.

BELTRÃO, Jane Felipe; OLIVEIRA, Assis da Costa. Movimentos, Povos \& Cidadanias Indígenas: Inscrições Constitucionais e Direitos Étnicos na América Latina. In BELTRÃO Jane Felipe; BRITO FILHO, Jose Claudio Monteiro de; GÓMEZ, Itziar; PAJARES, Emilio; PAREDES, Felipe; ZÚÑIGA, Yanira (Coords.). Derechos humanos de los grupos vulnerables, 2014, p. 251-284. Disponível em: 〈http://www.upf.edu/dhes-alfa/materiales/>. Acesso em 08 jun. 2016.

BENATTI, José Heder. Direito de propriedade e proteção ambiental no Brasil: apropriação e uso dos recursos naturais no imóvel rural. Belém: Tese de Doutorado, 2003.

BENCHIMOL, Samuel. Amazônia: Formação Cultural e Social. Manaus: Editora Valer, 2009.

BRASIL. Colecção das Decisões do Governo no Império do Brazil de 1821. Rio de Janeiro: Imprensa Nacional, 1889.

Colecção das Decisões do Governo no Império do Brazil de 1822. Rio de Janeiro: Imprensa Nacional, 1887.

Constituição Brasileira de 1824. Disponível em: <http://www2.senado.leg.br/bdsf/bitstream/handle/id/137569/Constituicoes_Brasileiras_v1_1 824.pdf?sequence=5>. Acesso em 04 jan 2016. 1849.

Coleção das leis do Império do Brasil de 1848. Rio de Janeiro: Typografia Nacional,

Lei 601 de 18 de Setembro de 1850 - Dispõe sobre as terras devolutas do Império. Disponível em: <http://www.planalto.gov.br/ccivil_03/LEIS/L0601-1850.htm>. Acesso em 06 jan 2016.

Decreto $n^{\circ} 1.318$ de 30 de janeiro de 1854 - Manda executar a lei $n^{\circ} 601$ de 18 de setembro de 1950. Disponível em: <http://legis.senado.gov.br/legislacao/ListaTextoIntegral.action?id=75492\&norma=102306>. Acesso em 06 jan 2016. 
Decreto $\mathrm{n}^{\mathrm{o}} \mathbf{5 . 6 5 5}$ de 3 de junho de 1874. Disponível em: <http://www.camara.gov.br/internet/infdoc/conteudo/colecoes/legislacao/legimpcd06/leis1874-v1e2/pdf75.pdf\#page=1>. Acesso em 06 jun 2016.

Coleção das Decisões do Governo do Império do Brasil de 1851. Rio de Janeiro: Typografia Nacional, 1852.

Coleção das Decisões do Governo do Império do Brasil de 1863. Rio de Janeiro: Typografia Nacional, 1864.

CARDOSO, Fernando Henrique; MÜLLER, Geraldo. Amazônia: expansão do capitalismo. 2008. Disponível em: <http://static.scielo.org/scielobooks/mnx6g/pdf/cardoso9788599662731.pdf>. Acesso em 17 jul. 2016.

CARVALHO, José Murilo de. Modernização frustrada: a política de terras do Império. Revista Brasileira de História, n.o 1, 1981, pp. 39-57.

COSTA, Célio Juvenal; CRUBELATI, Ariele Mazoti; LEMES, Amanda Barbosa; MONTAGNOLI, Gilmar Alves. História do Direito Português no período das Ordenações Reais. Congresso Internacional de História. Vol. 20. No. 07. 2011. Disponível em: <http://www. cih. uem. br/anais/2011/trabalhos/153.pdf>. Acesso em 28 dez 2015.

CHAMBOULEYRON, Rafael. Povoamento, ocupação e agricultura colonial (1649-1706). Belém: Editora Açaí, 2010.

CHAVES, Valena Jacob. A utilização de mão de obra escrava na colonização e ocupação da Amazônia. Os reflexos da ocupação das distintas regiões da Amazônia nas relações de trabalho que se formaram nestas localidades. In: VELLOSO, Gabriel; MARANHÃO, Ney (coord). Contemporaneidade e Trabalho - aspectos materiais e processuais. Estudos em homenagem aos 30 anos da AMATRA 8. São Paulo: LTr, 2011.

DE MESQUITA, Helena Angélica. Espaço agrário brasileiro: exclusão e inclusão social. Boletim Goiano de Geografia, v. 28, n. 1, p. 127-142, 2008.

FERREIRA, Eliana Ramos. Em cumprimento ao edital do reverendo vigário: os registros paroquiais no Pará - 1854-1860 (conflitos e tensões). Belém: Revista de História Econômica \& Economia Regional Aplicada - Vol. 7 Nº 13, 2012.

FISHER, Luly Rodrigues da Cunha. Universidade Federal do Pará/ Universidade de Paris XIII: Ordenamento Territorial e Planejamento Municipal - estudo de caso das limitações supralocais à aplicação do art. 30, viii da constituição de 1988 pelo município de Parauapebas, Pará. 2014. 624 f. Tese (Doutorado em Direito) - Universidade Federal do Pará/ Universidade de Paris XIII, Instituto de Ciências Jurídicas/ Centre de Recherche Sur l'Action Locale, Belém, 2014.

FREITAS, Augusto Teixeira de. Terras e Colonisação. Rio de Janeiro: B. L. Garnier, 1882.

HOLSTON, James. Cidadania Insurgente: Disjunções da democracia e da modernidade no Brasil. São Paulo: Companhia das Letras, 2013. 
MACHADO, Luciana de Oliveira Rosa. Uma nova lei de terras para a Amazônia: o caso de Santarém, Pará. Universidade de Brasília. Brasília: Tese de Doutorado. 2011.

MARTINS, José de Souza. Os camponeses e a política no Brasil: as lutas sociais no campo e o seu lugar no processo político. 3a ed. Petrópolis: Vozes, 1986.

. A vida privada nas áreas de expansão da sociedade brasileira. In. NOVAIS, Fernando A; SCHWARCZ, Lilia Moritz. (Orgs). História da vida privada no Brasil. vol 4. São Paulo: Companhia das Letras, 1998.

MATTOS NETO, Antônio José. A questão agrária no Brasil: aspecto sócio-jurídico. Revista do Programa de Estudos Pós-Graduados de História, v. 33, n. 1, 2009.

MEIRA FILHO, Augusto. Evolução Histórica de Belém do Grão Pará. Belém: Grafisa, 1976.

MOTTA, Marcia Maria Menendes. The Sesmarias In Brazil: colonial Land Policies In The Late Eighteenth-Century. E-journal of Portuguese History, v. 3, n. 2, p. 2, 2005.

MUNIZ, João de Palma. Patrimônio dos Conselhos Municipais do Estado do Pará. Belém: Aulliard \& C., 1904.

Legislação de Terras: Dados estatísticos. Belém: Oficina Gráfica do Instituto Lauro Sodré, 1924.

NOZOE, Nelson. Sesmarias e apossamento de terras no Brasil colônia. Revista EconomiA, v. 7, n. 3, p. 587-605, 2006.

NUNES, Francivaldo Alves. A Amazônia e a formação do Estado Imperial no Brasil: unidade do território e expansão de domínio. Almanack, n. 3, 2012.

PARÁ. Decreto $\mathrm{n}^{\circ} \mathbf{4 1 0}$ de 8 de outubro de 1891. Disponível em: $<$ https://arisp.files.wordpress.com/2009/07/decreto-estadual-n-c2ba-410-de-8-de-outubro-de18911.pdf>. Acesso em 04 jan 2016.

PRADO JÚNIOR, Caio. História Econômica do Brasil. São Paulo: Ed. Brasiliense, 1977.

REIS, Arthur Cézar Ferreira. Amazônia e a integridade do Brasil. Brasília: Senado Federal, 2001.

ROCHA, Ibraim; TRECCANI, Girolomo Domenico; BENATTI, José Heder; HABER, Lilian Mendes; CHAVES, Rogério Arthur Friza. Manual de Direito Agrário Constitucional: lições de direito agroambiental. Belo Horizonte: Forúm, 2010. 
ROCHA, Ana Luisa Santos. Populações tradicionais e o acesso à terra na Amazônia: uma "nova" reforma agrária e a compatibilização de direitos culturais, territoriais e ambientais. 2014. Disponível em: <http://www.publicadireito.com.br/artigos/?cod=956f9d4b926a8af0>. Acesso em 02 set 2016.

TRECCANI, Girolomo Domenico. Violência e Grilagem: Instrumentos de Aquisição da Propriedade da Terra no Pará. Belém: UFPA, ITERPA, 2011.

O Título de posse e a legitimação de posse como formas de aquisição da propriedade. Belém: Procuradoria Geral do Estado do Pará, n. 20, p. 121-158, 2009.

VIRGOLINO, José. A economia extrativa amazônica e a questão da oferta de trabalho: 18501890. CLIO: Revista de Pesquisa Histórica, v. 1, n. 13, 2015. 